\title{
The 5' Third of Cauliflower mosaic virus Gene VI Conditions Resistance Breakage in Arabidopsis Ecotype Tsu-0
}

\author{
K. Agama, S. Beach, J. Schoelz, and S. M. Leisner
}

First, second, and fourth authors: Department of Biological Sciences, University of Toledo, Toledo, OH 43606; and third author: Plant Science Unit, College of Agriculture, Food and Natural Resources, University of Missouri-Columbia, Columbia 65211.

Current address of S. Beach: Division of Research, Department of Obstetrics and Gynecology, 3055 Arlington Avenue, Medical College of Ohio, Toledo 43614.

Accepted for publication 23 October 2001.

\begin{abstract}
Agama, K., Beach, S., Schoelz, J., and Leisner, S. M. 2002. The $5^{\prime}$ third of Cauliflower mosaic virus gene VI conditions resistance breakage in Arabidopsis ecotype Tsu-0. Phytopathology 92:190-196.

Arabidopsis thaliana ecotypes vary in their responses to viruses. In this study, we analyzed the variation in response of $A$. thaliana ecotype Tsu-0 to Cauliflower mosaic virus (CaMV). This ecotype was previously reported to be resistant to two CaMV isolates (CM1841 and CM4-184), but susceptible to W260. In this study, we show that Tsu-0 is resistant to four additional CaMV isolates. CaMV propagated within the rosette leaves of Tsu-0 plants, but did not appear to spread systemically into the in-

In their native environments, plants are exposed to several types of pathogens (1). To respond to pathogens, plants possess resistance genes whose products control or prevent pathogen infection and disease development $(19,42)$. Plant resistance gene products often inhibit specific steps in the life cycle of a pathogen $(1,16)$. Interestingly, a resistance gene product may act by more than one pathway to protect the plant from a pathogen (6). In some cases, the viral genes involved in the resistance response have been determined through the discovery of resistance-breaking viruses and viral synergism $(2,24-26,33,40)$. Viruses may overcome resistance by either an active or a passive mechanism. For example, the potyvirus helper component-proteinase (HC-Pro) gene product inhibits gene silencing $(2,24)$. This permits resistance to be overcome because gene silencing is apparently a plant defense mechanism $(45,47)$. Viruses can also overcome resistance by a passive

florescence. However, virus viability in rosette leaves of Tsu-0 plants apparently was not compromised because infectious CaMV could be recovered from these organs. W260 overcomes Tsu-0 resistance by a passive mechanism (i.e., this virus avoids activating plant defenses). The portion of the viral genome responsible for W260 resistance breakage was mapped to the $5^{\prime}$ third of gene VI, which we have termed RBR-1. This region is also responsible for controlling the ability of CaMV to infect different types of solanaceous plants. Hence, the pathways by which plants of different families interact with CaMV may be conserved through evolution.

Additional keywords: virus resistance.

$\mathrm{CaMV}$ is useful for studying virus-host interactions for several reasons, not the least of which is its ability to infect $A$. thaliana (29). The double-stranded, circular DNA genome of this plant pararetrovirus is packaged within particles that are $50 \mathrm{~nm}$ in diameter $(22,31,37)$. The CaMV genome encodes seven to eight proteins. One of the more interesting proteins is that encoded by gene VI. Gene VI encodes a multifunctional protein involved in inclusion body formation, translation of viral genes, control of symptom expression, induction of the hypersensitive response (HR), and regulation of CaMV host range (3,8,13-15,17,26, 35,36,39-42). Using chimeric CaMV genomes, we demonstrate that the $5^{\prime}$ third of gene VI controls the capacity of the W260 isolate to overcome the resistance of $A$. thaliana ecotype Tsu- 0 by a passive mechanism. Furthermore, this resistance appears to prevent the systemic spread of four additional CaMV isolates.
\end{abstract} process. For example, Potato virus $X$ strain HB overcomes $R x$ gene-mediated resistance (27). This strain harbors a coat protein lacking a determinant needed to activate the $R x$ gene-mediated resistance pathway.

The cruciferous plant Arabidopsis thaliana has been useful for studying a variety of host-pathogen interactions (28). For example, the semidominant Carl gene of A. thaliana ecotype En-2 confers resistance to most isolates of Cauliflower mosaic virus (CaMV) $(9,29,44)$. Carl inhibits the systemic spread of CaMV (30) and defense-related genes are activated in this plant upon virus infection (9). However, the En-2 ecotype is not resistant to CaMV isolate NY8153 nor to Turnip mosaic virus (44). These data indicate that resistance may be virus strain and isolate specific. However, the NY8153 gene or genes permitting the virus to overcome En-2 resistance are currently unknown.

Corresponding author: S. M. Leisner; E-mail address: sleisne@uoft02.utoledo.edu

Publication no. P-2001-1217-03R

(C) 2002 The American Phytopathological Society

\section{MATERIALS AND METHODS}

A. thaliana ecotypes and virus inoculations. A. thaliana ecotypes Tsu- 0 and Col- 0 used in this study were provided by $\mathrm{S}$. H. Howell (Iowa State University, Ames). Seeds for these ecotypes were planted in moistened Redi Earth potting soil (BFG Supply, Burton, $\mathrm{OH})$. Plants were propagated in a growth chamber under continuous light of $60 \mu \mathrm{E} \mathrm{m} \mathrm{m}^{-2} \mathrm{~s}^{-1}$ of photosynthetic active radiation (PAR) at $20^{\circ} \mathrm{C}$ and fertilized with mineral nutrient solution as described previously (44).

Cloned viral DNA for CaMV isolate CM1841 (20) was provided by S. H. Howell. CaMV isolate W260 (21), as well as the chimeric viruses CaMVH30, CaMVH31, CaMVH33, CaMVH72, CaMVH82, and CaMVH84, were reported previously $(40,46)$. CaMV isolates NY8153 (11), D/H (5), Cabb S (18), and CMV-1 (10) were provided by U. Melcher (Oklahoma State University, Stillwater). CaMV strain CaN (23) was provided by K. Richards (Institut de Biologie Moleculaire des Plants du CNRS et de l'ULP, France). All CaMV isolates and chimeras were maintained in tur- 
nips (Brassica campestris L. var. rapa 'Just Right') by serial passage in a greenhouse at $22^{\circ} \mathrm{C}$ under natural lighting (29).

A. thaliana ecotypes Col-0 and Tsu-0 were inoculated at the sixleaf-stage with sap prepared from symptomatic turnip plants. Sap was prepared by harvesting turnip leaves infected with the appropriate virus and grinding in $3 \mathrm{ml}$ of inoculation buffer $(10 \mathrm{mM}$ potassium acetate, $\mathrm{pH}$ 7.2) per gram of tissue. Celite was added and the suspension was mixed and rub-inoculated onto rosette leaves three, four, and five of $A$. thaliana plants with a plastic spatula (44). Following inoculation, A. thaliana plants were propagated in a growth chamber under a regime of $12 \mathrm{~h}$ of light (at $60 \mu \mathrm{E} \mathrm{m} \mathrm{m}^{-2} \mathrm{~s}^{-1} \mathrm{PAR}$ ) and $12 \mathrm{~h}$ of dark at $20^{\circ} \mathrm{C}$ and fertilized with mineral nutrient solution as described previously (44). Plants were observed daily for symptom production up to 52 days postinoculation (DPI). Each experiment was performed at least two to three times with 15 to 20 plants of each ecotype inoculated per experiment. Although the inoculation efficiencies for this work appear somewhat low, they are typical for this type of experiment (29, 30,44).

Coinoculation experiments. A. thaliana ecotypes Tsu- 0 and Col-0 were inoculated with plant sap from turnips infected with $\mathrm{CaN}$ or W260, or with a mixture of sap containing both viruses. The inoculum for single viral isolates was prepared as described above. Mixtures were prepared by grinding CaN- or W260-infected turnip tissue with $1 \mathrm{ml}$ of inoculation buffer per gram of tissue to make a $3 \times$ inoculum. The concentrated inoculum allowed the virus to be diluted threefold and still retain the same CaMV concentration as for a normal inoculation, as described previously. This permitted three different mixture concentrations to be prepared from these inocula: (i) $1 \mathrm{ml}$ of sap from CaN-infected turnip tissue with $1 \mathrm{ml}$ of W260 sap and $1 \mathrm{ml}$ of inoculation buffer (1:1 mixture); (ii) $2 \mathrm{ml}$ of CaN sap with $1 \mathrm{ml}$ of W260 sap (2:1 mixture); and (iii) $1 \mathrm{ml}$ of CaN sap with $2 \mathrm{ml}$ of W260 sap (1:2 mixture). The viruses and mixtures were inoculated onto Col-0 and Tsu-0 plants as described previously (44). Three trials were conducted for each experiment with 15 to 20 plants per pot and two pots for each treatment.

Polymerase chain reaction analyses. The presence of viral DNA in infected plants was detected using polymerase chain reaction (PCR). The extraction procedure used to isolate and amplify viral DNA from infected plant tissue was derived from that described by Callaway et al. (9). All of the inoculated Tsu- 0 and Col-0 plants from a pot (15 to 20 plants) were harvested by 52 DPI and separated into rosette leaf and cauline leaf/flower stalk tissue. The rosette leaves from all of the plants in each pot were pooled together. It is important to note that this pooled tissue included inoculated and uninoculated rosette leaves. Likewise, all of the cauline leaf/flower stalk tissue from all plants in each pot was pooled.

Tissue was ground in extraction buffer $(250 \mathrm{mM} \mathrm{NaCl}, 0.25 \%$ sodium dodecyl sulfate, $30 \mathrm{mM}$ EDTA, and $100 \mathrm{mM}$ Tris, $\mathrm{pH}$ 8) at a concentration of $1 \mathrm{ml}$ of buffer per gram of tissue. The extract was incubated with $10 \mu$ lof proteinase $\mathrm{K}(10 \mathrm{mg} / \mathrm{ml})$ per $\mathrm{ml}$ of tissue extract at $55^{\circ} \mathrm{C}$ for $60 \mathrm{~min}$. The extract was diluted with an equal volume of distilled water and incubated at 95 to $100^{\circ} \mathrm{C}$ for 8 to $10 \mathrm{~min}$. The samples were permitted to cool, centrifuged at $13,000 \times g$ for $5 \mathrm{~min}$, and the supernatants were used as templates for PCR analyses.

PCR reactions were conducted in a $100-\mu$ l total volume that contained a final concentration of $50 \mathrm{mM} \mathrm{KCl}, 1.5 \mathrm{mM} \mathrm{MgCl}$, $10 \mathrm{mM}$ Tris- $\mathrm{HCl}$ (pH 9.0), 0.1\% Triton X-100, $200 \mu \mathrm{M}$ for all four deoxynucleotide triphosphates, 0.5 units of Taq DNA polymerase (Promega Corporation, Madison, WI), and $2 \times 10^{-7} \mathrm{M}$ for the CM42F (5'-GGAAACAGTGCTTCATCCTC-3') and CM42R (5'TCGCTGCAACGGCTTCTAAG-3') primers (synthesized by DNA International Inc., Lake Oswego, OR). To this mixture, either 10 $\mu \mathrm{l}$ of infected plant tissue extract or $10 \mathrm{ng}$ of pCaMV10 (20), pCaMVW260 $(21,40)$, or pCaN (23) DNA was added as a tem- plate. The PCR program consisted of a five-cycle preamplification step of $30 \mathrm{~s}$ at $92^{\circ} \mathrm{C}, 90 \mathrm{~s}$ at $35^{\circ} \mathrm{C}$, and $40 \mathrm{~s}$ at $72^{\circ} \mathrm{C}$, followed by a single elongation step of $1 \mathrm{~min}$ at $95^{\circ} \mathrm{C}$ and $5 \mathrm{~min}$ at $72^{\circ} \mathrm{C}$. Finally, a 35-cycle amplification step of $30 \mathrm{~s}$ at $94^{\circ} \mathrm{C}, 30 \mathrm{~s}$ at $45^{\circ} \mathrm{C}$, and $40 \mathrm{~s}$ at $72^{\circ} \mathrm{C}$ was performed. The amplifications were performed in a TempTronic/Amplitron Programmable Thermal Cycler (Barnstead-Thermolyne, Dubuque, IA). The CM42F/CM42R primer pair directs the amplification of a 724-bp fragmentspanning gene II from all viruses and chimeras tested in this study, except for $\mathrm{CaN}$. The $\mathrm{CaN}$ fragment is $430 \mathrm{bp}$ in length. PCR products were fractionated by electrophoresis through a $1.5 \%$ agarose gel in $1 \times$ Tris-borate EDTA buffer (4). Each set of reactions was tested at least twice for each set of inoculated plants.

\section{RESULTS}

A. thaliana ecotype Tsu-0 is resistant to CaMV. A. thaliana ecotypes were previously reported to vary in their susceptibility to CaMV isolates $(9,29)$. Ecotypes such as Col-0 are typically susceptible to CaMV, including CM1841 and W260 $(29,30)$ (Table 1). Col-0 plants infected with CM1841 developed vein clearing and chlorosis on rosette and cauline leaves as well as chlorosis and stunting of the flower stalk (Fig. 1). Col-0 plants infected with W260 showed similar symptoms, but the flower stalks were usually more severely stunted. Symptoms in both cases appeared by 23 to $25 \mathrm{DPI}$.

As reported previously (29), Tsu-0 plants inoculated with CM1841 showed no symptoms (Fig. 1; Table 1), whereas those infected with the W260 isolate developed severe systemic symptoms (e.g., stunting and chlorosis of the rosette leaves). If the flower stalks and cauline leaves developed on W260-infected Tsu0 plants, they were chlorotic and severely stunted, but these plants frequently died before they flowered $(\approx 52 \mathrm{DPI})$. In no case were necrotic lesions observed on leaves of Tsu- 0 plants inoculated with either virus.

The initial evaluation of Tsu- 0 plants involved only three isolates (29); therefore, it was important to extend these studies to other CaMV isolates. Thus, four additional CaMV isolates (Cabb $\mathrm{S}, \mathrm{CMV}-1, \mathrm{D} / \mathrm{H}$, and NY8153) were tested for their capacity to overcome resistance in Tsu-0 plants. All four isolates induced systemic infections in Col-0 (Table 1), showing the typical CaMVinduced chlorosis and stunting of the plants beginning 23 to 25 DPI. In contrast, none of the four isolates induced symptoms on either the inoculated or noninoculated portions of Tsu-0 plants.

CaMV resistance in Tsu-0 plants prevents invasion of inflorescence organs. To gain insight into Tsu-0 resistance, the distribution of CaMV DNA in plants inoculated with CM1841 and W260 was determined with PCR (9). Col-0 plants inoculated with

TABLE 1. Susceptibility of Arabidopsis thaliana ecotypes to systemic infection by Cauliflower mosaic virus isolates ${ }^{\mathrm{a}}$

\begin{tabular}{lll}
\hline Virus & Col-0 & Tsu-0 \\
\hline Cabb S & $18 / 50(36)$ & $0 / 53(0)$ \\
CaN & $12 / 54(22)$ & $0 / 50(0)$ \\
CM1841 & $82 / 225(36)$ & $0 / 225(0)$ \\
CMV-1 & $17 / 37(46)$ & $0 / 38(0)$ \\
D/H & $21 / 57(37)$ & $0 / 57(0)$ \\
NY8153 & $17 / 73(23)$ & $0 / 75(0)$ \\
W260 & $58 / 225(26)$ & $61 / 253(24)$ \\
Mixtures & & \\
$1: 1$ & $26 / 90(29)$ & $0 / 90(0)$ \\
$2: 1$ & $25 / 90(28)$ & $0 / 90(0)$ \\
$1: 2$ & $24 / 90(27)$ & $0 / 90(0)$ \\
\hline
\end{tabular}

a Number of plants showing symptoms by 52 days postinoculation out of the total number of plants analyzed. The percentage of infected plants is given in parentheses. The numbers are a summary of at least two experiments with 15 to 20 plants per experiment. Only two experiments were done for CMV-1; eight experiments were done for CM1841 and W260.

${ }^{\mathrm{b}}$ Indicates the ratio of $\mathrm{CaN}$ to W260 in coinoculations. 
either virus, as well as noninoculated Tsu- 0 and Col-0 plants, served as controls. CaMV DNA for both viruses was detected in both the rosette leaf and cauline leaf/flower stalk portions of W260- and CM1841-infected Col-0 plants (Fig. 2). It is important to note that the rosette tissue examined for all PCR experiments included both inoculated and uninoculated leaves. Viral DNA of both viruses also was detected in rosette leaf tissues for Tsu-0 plants. However, only W260 DNA was detected in the cauline leaf/flower stalk portions of Tsu-0 plants. These results were consistent for two separate experiments.

In addition to CM1841 and W260, PCR analyses were perormed to determine the distribution of CaMV DNA in Col-0 and Tsu-0 plants inoculated with the Cabb S, CMV-1, D/H, or NY8153 CaMV isolates. Viral DNA of all four viral isolates was detected in both rosette leaf and cauline leaf/flower stalk portions of infected Col-0 plants (Fig. 2), but only in the rosette leaves of Tsu- 0 plants. Identical results were obtained both times these experiments were performed.

To determine if CM1841 viability was compromised in Tsu-0 plants, 20 Tsu-0-inoculated plants within a pot were harvested and divided into rosette leaf and cauline leaf/flower stalk tissue; the same organs were pooled together. A pot of 20 CM1841-infected Col-0 plants also was harvested and analyzed in the same manner as a control. These tissues were ground in inoculation buffer and inoculated onto turnip plants as described previously. Turnips inoculated with sap derived from the rosette portions of CM1841infected Tsu-0 plants developed chlorotic lesions and vein-clearing symptoms by 30 DPI. However, no symptoms were induced in turnips by 60 DPI, when they were inoculated with sap derived from the asymptomatic cauline leaf/flower stalk portions of CM1841-infected Tsu-0 plants. Turnips inoculated with sap prepared from either rosette leaf or cauline leaf/flower stalk tissue from Col-0 plants infected with CM1841 developed chlorotic lesions and vein-clearing symptoms. Turnips inoculated with tissue from either portion of Tsu-0 plants inoculated with W260 de- veloped chlorotic lesions, vein-clearing, and stunting symptoms typical of that virus.

W260 overcomes Tsu-0 resistance via a passive mechanism. To determine if W260 either actively or passively overcomes resistance, Tsu- 0 and Col-0 plants were inoculated with mixtures of the $\mathrm{W} 260$ and the $\mathrm{CaN}$ isolates of $\mathrm{CaMV}$. CaN was previously described by Jupin et al. (23) and consists of a CM4-184 CaMV genome in which gene II was replaced with the $N$ gene from Beet necrotic yellow vein virus. The $N$ gene insert for $\mathrm{CaN}$ is only $190 \mathrm{bp}$ in length, whereas the wild-type gene II harbored by W260 is 479 bp. Thus, it is possible to detect DNA for both CaN and W260 in a mixture by PCR (Fig. 3).

Col-0 plants inoculated with either virus alone or with 1:1, 1:2, or 2:1 mixtures of CaN/W260 developed systemic symptoms (Table 1), including chlorosis and vein clearing on the rosette and cauline leaves and stunting of the flower stalk. The symptoms induced by $\mathrm{CaN}$ on Col-0 were identical to those incited by CM1841 as well as its CM4-184 progenitor (data not shown). In contrast, none of the Tsu- 0 plants inoculated with either of the three mixtures, or with $\mathrm{CaN}$ alone, developed symptoms. Only Tsu-0 plants inoculated with W260 alone developed the typical chlorotic lesion, vein-clearing, and stunting symptoms.

PCR analyses performed on tissue from Col-0 plants infected with either $\mathrm{CaN}$ or W260 alone revealed viral DNA within rosette leaves as well as in cauline leaf/flower stalk tissues (Fig. 3). Col-0 plants inoculated with 1:1, 1:2, or 2:1 ratios of W260 to CaN also were infected by both viruses in rosette leaf and in cauline leaf/ flower stalk tissues (only the 1:1 mixture is shown in Fig. 3). These data indicated that there was no interference between the W260 and CaN isolates in the infection of susceptible Col-0 plants.

PCR analysis of plant tissue from Tsu- 0 plants showed a different pattern. W260 DNA was detected in the rosette leaves and in the cauline leaf/flower stalk portions of infected Tsu-0 plants (Fig. 3). However, PCR analyses of Tsu-0 plants inoculated with
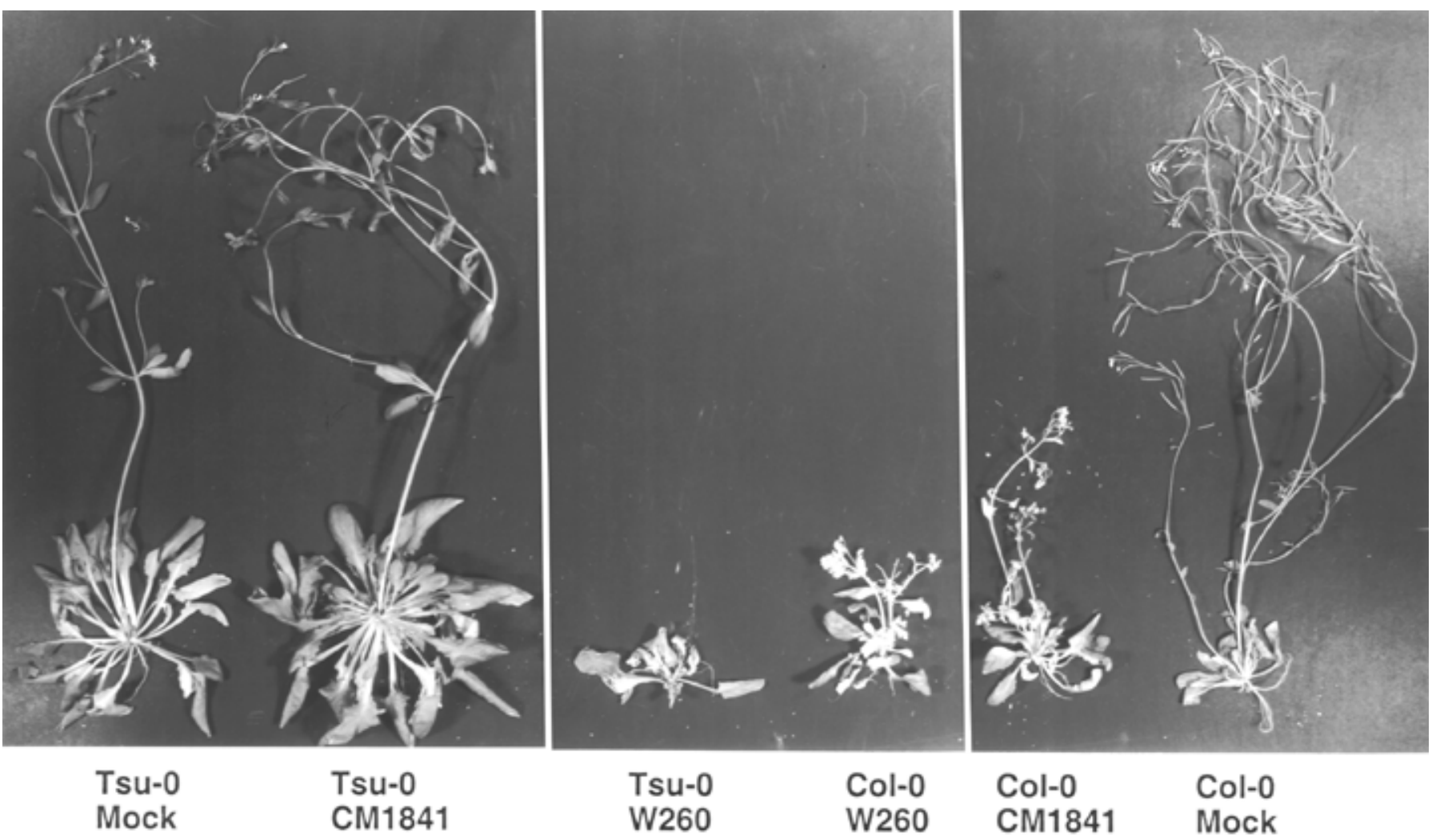

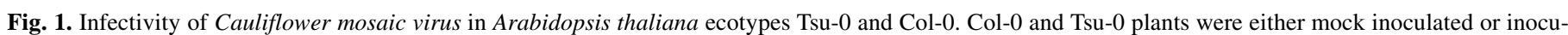
lated with either CM1841 or W260 and photographed 52 days postinoculation. 
$\mathrm{CaN}$ or with either of the three mixtures revealed viral DNA within the rosette leaf but not in the cauline leaf/flower stalk portions of these plants. Similar results obtained for two independent experiments.

The $5^{\prime}$ third of the gene VI region of CaMV isolate $\mathrm{W} 260$ allows for breakage of Tsu-0 resistance. W260 overcomes Tsu-0 resistance but CM1841 does not; therefore, it is possible to map the portion of the viral genome responsible for resistance breakage by using viral chimeras. Genetic chimeras have been used previously to identify several functions within the CaMV genome (35, 40,41,43). Therefore, this approach was used to examine Tsu-0 resistance breakage. The initial chimeras used in this study were viruses in which a region spanning the majority of gene VI and the large intergenic region was exchanged between W260 and CM1841 (Fig. 4) (40). By 23 to 25 DPI, both H30 and H31 induced systemic symptoms on Col-0 that were typical of CaMV on $A$. thaliana (i.e., chlorosis and vein clearing of leaves, chlorosis and stunting of the flower stalk). The situation with the Tsu-0 ecotype was quite different. The H30 virus (W260 + CM1841 gene VI) was unable to induce either local or systemic symptoms on Tsu-0 plants, whereas the H31 chimera (CM1841 + W260 gene VI) induced systemic symptoms on Tsu- 0 plants, including chlorosis and vein-clearing symptoms on leaves, and stunting of the flower stalk by 23 to 25 DPI. These data implicated gene VI, the adjacent intergenic region, or both as containing the determinant conferring the resistance-breaking ability on CaMV isolate W260.

To further localize the resistance-breaking determinant, the H84 and H82 chimeras (46) were employed. These two chimeras con- sist of W260 genomes in which large portions of gene VI and the intergenic region were replaced with the equivalent segment from CM1841 (Fig. 4). Both chimeras were able to systemically infect Tsu- 0 and Col-0 plants, inducing symptoms that were typical of CaMV infection in A. thaliana. The results obtained with these two chimeras suggested that the $5^{\prime}$ third of gene VI harbored the resistance-breaking determinant. To examine this hypothesis, two additional chimeras were tested, H72 and H33 (46). Whereas both $\mathrm{H} 72$ and $\mathrm{H} 33$ induced systemic infections in Col-0 that showed the typical CaMV symptoms, only the latter was able to systemically infect Tsu-0 plants.

To determine the distribution of the viral chimeras in Col-0 and Tsu-0 plants, PCR analyses were performed (Fig. 5). The PCR data agreed with the visible symptom data and were consistent for two independent experiments. CaMV DNA was detected in both the rosette leaf and the cauline leaf/flower stalk portions of Col-0 plants inoculated with all of the chimeras. Viral DNA also was detected in the rosette leaf portions of Tsu- 0 plants inoculated with all of the chimeras. However, CaMV DNA was only detected in the cauline leaf/flower stalk tissues of Tsu- 0 plants inoculated with $\mathrm{H} 31$, H84, H82, and H33, but not with $\mathrm{H} 72$ and $\mathrm{H} 30$.

\section{DISCUSSION}

A. thaliana ecotype Tsu-0 was previously reported to be resistant to CaMV isolates CM1841 and CM4-184, but susceptible to W260 (29). The work described here demonstrates that Tsu-0 resistance is active against four additional CaMV isolates. Previ-
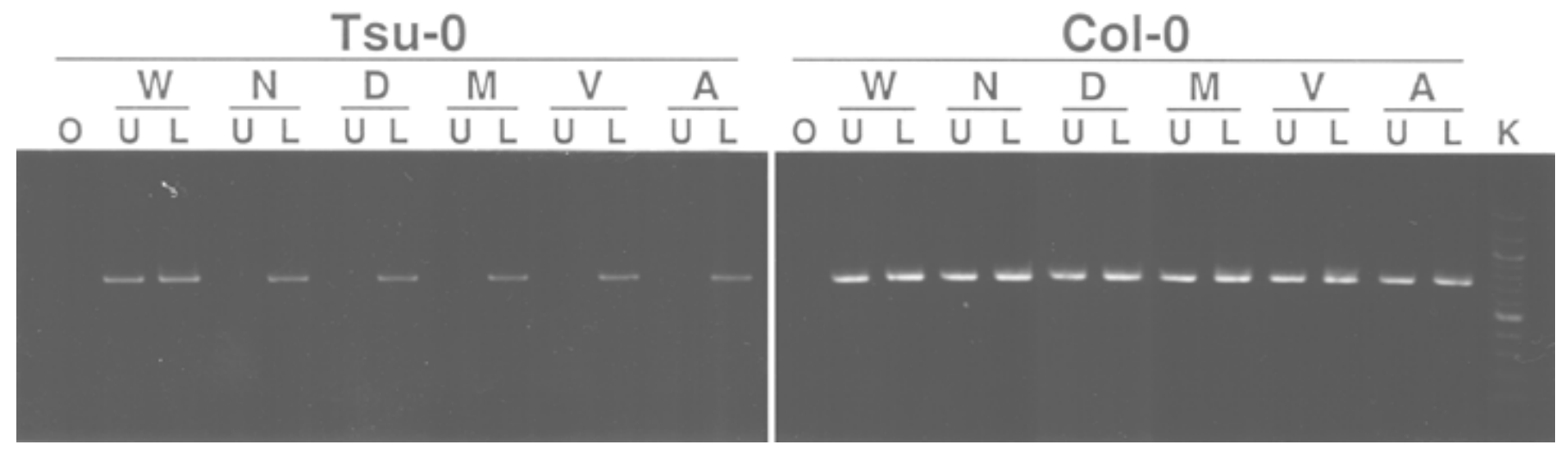

Fig. 2. Polymerase chain reaction (PCR) detection of Cauliflower mosaic virus (CaMV) in Arabidopsis thaliana ecotypes Tsu-0 and Col-0. Tsu-0 or Col-0 plants, either mock inoculated or inoculated with several Cauliflower mosaic virus isolates, were harvested 52 days postinoculation and analyzed by PCR. O = mock-inoculated plant. CaMV isolates: W260, W; NY8153, N; D/H, D; CM1841, M; CMV-1, V; and Cabb S, A. K indicates the New England Biolabs (Beverly, MA) 100-bp ladder. U indicates samples from cauline leaves/flower stalks; L indicates samples from rosette leaf tissue.

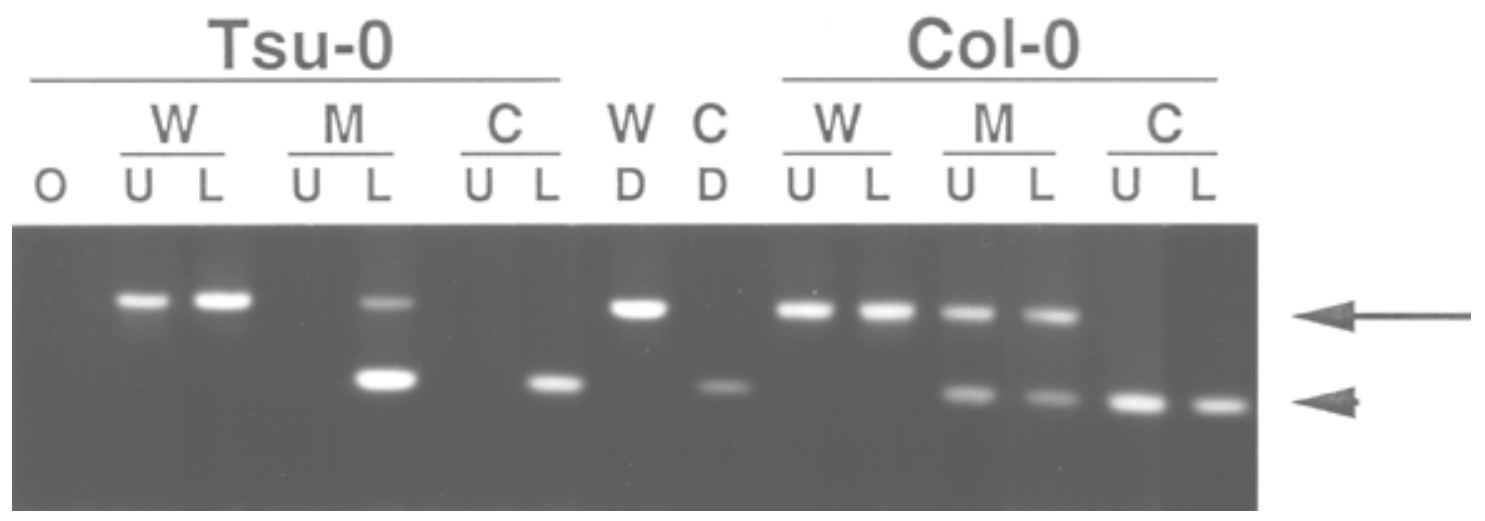

Fig. 3. Infectivity of Cauliflower mosaic virus isolates W260, CaN, or mixtures of W260 and CaN in Arabidopsis thaliana ecotypes Tsu-0 or Col-0. Tsu-0 or Col-0 plants inoculated with either CaN, C; W260, W; or a 1:1 mixture of the two viruses, M. Plant tissues were harvested at 52 days postinoculation and analyzed by polymerase chain reaction (PCR). O indicates mock-inoculated Tsu-0 plant; D indicates PCR product generated from plasmid DNA. U indicates PCR product generated from cauline leaf/flower stalk portions of the plants and L from rosette leaf tissue. Arrow shows location of the 724-bp W260 PCR fragment; arrowhead indicates the $430-$ bp $\mathrm{CaN}$ product. 
ous work (29) did not elucidate the nature of Tsu-0 resistance to CaMV. To examine this, PCR analyses were performed on Tsu- 0 plants inoculated with the CaMV isolates. We discovered that virus DNA was present in the rosette leaves but absent elsewhere in CM1841-inoculated Tsu- 0 plants. The same was true of Tsu-0 plants infected with CaMV isolates Cabb S, CMV-1, D/H, and NY8153. Analysis of CM1841-infected Tsu-0 plants by the plant skeleton hybridization method $(30,32)$, suggests that this virus not only is limited to the rosette leaves but is localized to the inoculated leaf (data not shown). Hence, Tsu- 0 appears to prevent invasion of the inflorescence by several CaMV isolates. Based on visible symptom data, Tsu-0 was resistant to several other CaMV isolates, including: Bari-1, BBC, Cabb B, and California (data not shown). It is likely that these viruses are also prevented from invading the inflorescence; therefore, this indicates that Tsu- 0 is resistant to systemic infection by most CaMV isolates. This suggests that CaMV isolate W260 may be unique in its interaction with Tsu-0 plants.

The inability of NY8153 to systemically infect Tsu- 0 plants is interesting because this virus isolate is able to overcome resistance in another A. thaliana ecotype, En-2 (44). We have shown here that gene VI from CaMV isolate W260 is necessary and sufficient for CM1841 to overcome Tsu-0 resistance. However, the viral genetic basis of NY8153 resistance breakage in En-2 plants appears to be more complex: NY8153 gene VI is not sufficient to confer resistance-breaking capacity to isolates unable to systemically infect En-2 plants (44). These data may indicate that $A$. thaliana ecotypes harbor resistance genes that place different requirements on CaMV isolates.

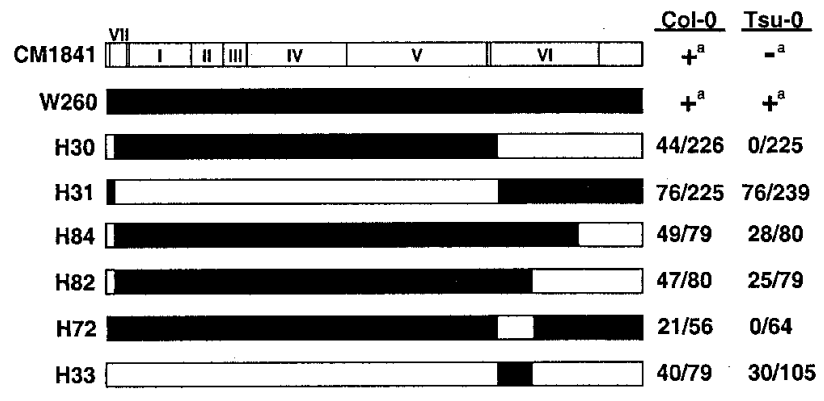

Fig. 4. Genetic map of Cauliflower mosaic virus (CaMV) chimeras. Linearized versions of the CaMV genomic map are shown $(40,46)$. Roman numerals indicate the locations of the various CaMV genes. The $5^{\prime}$ to $3^{\prime}$ coding of each gene is from left to right. The CM1841 (unshaded) and W260 (black) viral genomes are indicated. The number of plants showing systemic symptoms out of the total number of plants inoculated is shown. These numbers are from at least three experiments with 15 to 30 plants per experiment. ${ }^{a}$ Numerical data are given in Table 1.
However the resistance shown by Tsu- 0 is mediated, it apparently does not involve the HR because none of the CaMV isolates inoculated to that plant induced necrotic symptoms. Viable virus could be obtained from the rosette leaf portion of Tsu- 0 plants inoculated with CM1841 but not from the cauline leaf/flower stalk tissues. These data suggest that CM1841 is not completely eliminated from inoculated leaves. In addition, the lack of viable virus in the cauline leaf/flower stalk tissues suggests that the virus does not systemically invade the inflorescence.

In contrast to the other CaMV isolates, W260 was able to systemically infect Tsu- 0 plants. The W260 virus propagated and spread within the Tsu- 0 ecotype so efficiently that it often killed infected plants before they flowered. We do not believe that the difference between CM1841 and W260 on Tsu-0 is due to a difference in inoculum titer, because (i) we standardized the inoculum concentration by adding the same amount of buffer per gram of tissue and (ii) the virus levels per gram of infected turnip tissue (used for A. thaliana inoculum) are higher for CM1841 than for W260 (3). Taken together, this means that there should be sufficient CM1841 inoculum to cause a systemic infection in Tsu-0 plants if infection of Tsu- 0 were possible. Hence, it seemed more likely that there was a fundamental genetic difference between viruses such as CM1841 and W260 that permitted the latter to overcome Tsu-0 resistance.

To identify the portion of the viral genome responsible for this difference, we utilized viral chimeras constructed from CM1841 and W260. Analysis of these chimeras initially implicated gene VI as responsible for CaMV to infect Tsu- 0 plants. Analysis of additional chimeras localized the resistance-breaking determinant to the $5^{\prime}$ third of gene VI, which we have termed resistance-breaking region 1 (RBR-1). RBR-1 differs at 12 positions in nucleotide sequence between W260 and CM1841 (46). Notably, the $3^{\prime}$ portion of RBR-1 overlaps with the sequence of gene VI encoding the minimal translational transactivation domain (17). Therefore, it is possible that the translational transactivation efficiencies of the W260 and CM1841 gene VI products may differ, permitting W260 to overcome Tsu-0 resistance.

Gene VI has been shown to be a factor influencing CaMV longdistance movement and resistance responses in solanaceous plants (38-41). For example, CaMV isolate CM1841 elicits a resistance response in Nicotiana bigelovii, whereas W260 spreads systemically through this host (40). It is the RBR-1 region of gene VI that also controls resistance breakage in $N$. bigelovii (46). This may imply that the plant factors influencing the role of gene VI in systemic spread or resistance-breakage may be conserved between the Brassicaceae and the Solanaceae.

Resistance shown by Tsu- 0 plants could be overcome by either an active or passive process mediated by the W260 gene VI product. To address these possibilities, coinoculation experiments were

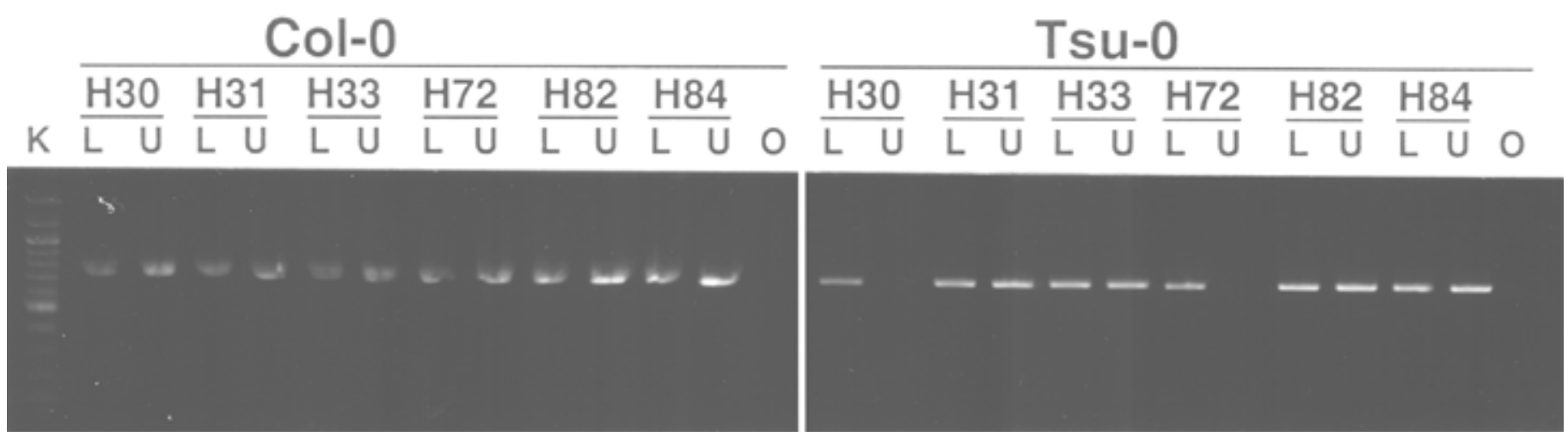

Fig. 5. Mapping of the domain of Cauliflower mosaic virus (CaMV) gene VI involved in overcoming resistance in Arabidopsis thaliana ecotype Tsu-0. Tsu-0 or Col-0 plants, either mock inoculated or inoculated with several CaMV chimeras, were harvested 52 days postinoculation and analyzed by polymerase chain reaction (PCR). K indicates the New England Biolabs (Beverly, MA) 100-bp ladder; O indicates mock-inoculated plant, either Tsu-0 or Col-0. L indicates PCR product generated from rosette leaf tissue and $\mathrm{U}$ from cauline leaf/flower stalk portions of the plants. 
performed. These experiments suggest that W260 overcomes Tsu0 resistance by evading the host recognition machinery, whereas other CaMV isolates, such as CM1841, appear to be recognized. When CaN and W260 were coinoculated onto Tsu-0 plants, the resistance pathway elicited by $\mathrm{CaN}$ apparently protected the plant against W260. These data suggest that gene VI does not act as a gene silencing suppresser like the potyvirus HC-Pro gene (2, 24). Rather, W260 infection of Tsu- 0 more closely resembles the situation with the capsid protein of Potato virus $X$ strain HB and its interactions with the potato $R x$ gene $(7,27)$. The $R x$ gene-mediated resistance appears to be an induced response; therefore, it is possible that Tsu-0 resistance may be generated via a similar pathway. This response is probably mediated by a signal because it is unlikely that all of the cells infected with W260 in Tsu- 0 plants also were infected with $\mathrm{CaN}$.

Our work indicates that gene VI of CaMV isolates such as CM1841 and CaN induces a resistance response in Tsu- 0 plants. Interestingly, gene VI can act as an avirulence gene in Nicotiana spp. Experiments with chimeric CaMVs or agroinfiltration experiments with gene VI indicate that this viral protein induces an HR in N. edwardsonii as well as production of pathogenesis-related proteins (34). However, not all resistance to CaMV in Nicotiana spp. is mediated via the HR. It is possible to separate the resistance in N. edwardsonii into two components, each controlled by a specific gene: a cell death component and a defense response independent of the HR (12). It is possible that Tsu-0 resistance operates via the second mechanism (i.e., a defense response that does not involve the HR). It is significant that the W260 RBR-1 region that permits Tsu- 0 resistance to be overcome also elicits a cell death response in $N$. clevelandii (26). The $N$. clevelandii HR appears to be conditioned by a single recessive host gene within the plant. Taken together, these data indicate that the W260 RBR1 region does not allow for evasion of host defenses in all plant species.

In summary, Tsu-0 resistance is mediated by prevention of CaMV systemic invasion of the inflorescence. This resistance is overcome by W260, which apparently is not recognized by the Tsu-0 host. The region of W260 responsible for overcoming resistance is the $5^{\prime}$ third of gene VI, which we have termed RBR-1. The identification of RBR-1 will now permit studies to identify the precise genetic determinants responsible for overcoming Tsu-0 resistance.

\section{ACKNOWLEDGMENTS}

This work was supported in part by the University of Toledo deARCE Memorial Endowment Fund in Support of Medical Research and Development Program and USDA award 96-3503-3284. We thank S. H. Howell (Iowa State University, Ames) and U. Melcher (Oklahoma State University, Stillwater) for providing us with the CaMV isolates; S. Goldman and the University of Toledo Plant Science Research Center for their help and support; J. Haidet and V. Kocsis for their assistance with PCR analyses; and the Arabidopsis Biological Resource Center at the Ohio State University for their assistance with Arabidopsis propagation.

\section{LITERATURE CITED}

1. Agrios, G. N. 1988. Plant Pathology, 3rd ed. Academic Press, San Diego, CA.

2. Anandalakshmi, R., Pruss, G. J., Ge, G., Marathe, R., Mallory, A. C., Smith, T. H., and Vance, V. B. 1998. A viral suppressor of gene silencing in plants. Proc. Natl. Acad. Sci. USA 95:13079-13084.

3. Anderson, E. J., Qiu, S. G., and Schoelz, J. E. 1991. Genetic analysis of determinants of disease severity and virus concentration in cauliflower mosaic virus. Virology 181:647-655.

4. Ausubel, F. M., Brent, R., Kingston, R. E., Moore, D. D., Seidman, J. G., Smith, J. A., and Struhl, K. 1993. Current Protocols in Molecular Biology. Greene Publishing Associates and John Wiley \& Sons, Inc., Cambridge, MA

5. Balazs, E., Guilley, H., Jonard, G., and Richards, K. 1982. Nucleotide sequence of DNA from an altered-virulence isolate $\mathrm{D} / \mathrm{H}$ of the cauli- flower mosaic virus. Gene 19:239-249.

6. Bendahmane, A., Kanyuka, K., and Baulcombe, D. C. 1999. The $R x$ gene from potato controls separate virus resistance and cell death responses. Plant Cell 11:781-791.

7. Bendahmane, A., Kohm, B. A., Dedi, C., and Baulcombe, D. C. 1995. The coat protein of potato virus $\mathrm{X}$ is a strain-specific elicitor of $R x 1$ mediated virus resistance in potato. Plant J. 8:933-941.

8. Bonneville, J. M., Sanfacon, H., Futterer, J., and Hohn, T. 1989. Posttranscriptional trans-activation in cauliflower mosaic virus. Cell 59: 1135-1143.

9. Callaway, A., Liu, W., Adrianov, V., Stenzler, L., Zhao, J., Wettlaufer, S., Jayakumar, P., and Howell, S. H. 1996. Characterization of cauliflower mosaic virus (CaMV) in virus-resistant ecotypes of Arabidopsis. Mol. Plant-Microbe Interact. 9:810-818.

10. Chenault, K. D., and Melcher, U. 1993. Cauliflower mosaic virus isolate CMV-1. Plant Physiol. 101:1395-1396.

11. Chenault, K. D., Steffens, D. L., and Melcher, U. 1992. Nucleotide sequence of cauliflower mosaic virus isolate NY8153. Plant Physiol. 100:542-545.

12. Cole, A. B., Kiraly, L., Ross, K., and Schoelz, J. E. 2001. Uncoupling resistance from cell death in the hypersensitive response of Nicotiana species to Cauliflower mosaic virus infection. Mol. Plant-Microbe Interact. 14:31-41.

13. Covey, S., and Hull, R. 1981. Transcription of cauliflower mosaic virus DNA. Detection of transcripts, properties, and location of the gene encoding the virus inclusion body protein. Virology 111:463-474.

14. Daubert, S., and Routh, G. 1990. Point mutations in cauliflower mosaic virus gene VI confer host-specific symptom changes. Mol. PlantMicrobe Interact. 3:341-345.

15. Daubert, S. D., Schoelz, J., Debao, L., and Shepherd, R. J. 1984. Expression of disease symptoms in cauliflower mosaic virus genomic hybrids. J. Mol. Appl. Genet. 2:537-547.

16. Dawson, W. O., and Hilf, M. E. 1992. Host-range determinants of plant viruses. Annu. Rev. Plant Physiol. Plant Mol. Biol. 43:527-555.

17. De Tapia, M., Himmelbach, A., and Hohn, T. 1993. Molecular dissection of the cauliflower mosaic virus translation transactivator. EMBO J. 12: 3305-3314.

18. Franck, A., Guilley, H., Jonard, G., Richards, K., and Hirth, L. 1980. Nucleotide sequence of cauliflower mosaic virus DNA. Cell 21:285-294.

19. Fraser, R. S. S. 1986. Genes for resistance to plant viruses. CRC Crit. Rev. Plant Sci. 3:257-294.

20. Gardner, R. C., Howarth, A. J., Hahn, P., Brown-Luedi, M., Shepherd, R. J., and Messing, J. 1981. The complete nucleotide sequence of an infectious clone of cauliflower mosaic virus by M13mp7 shotgun sequencing. Nucleic Acids Res. 9:2871-2888.

21. Gracia, O., and Shepherd, R. J. 1985. Cauliflower mosaic virus in the nucleus of Nicotiana. Virology 146:141-145.

22. Hull, R., and Covey, S. N. 1985. Cauliflower mosaic virus: Pathways of infection. BioEssays 3:160-163.

23. Jupin, I., Guilley, H., Richards, K. E., and Jonard, G. 1992. Two proteins encoded by beet necrotic yellow vein virus RNA 3 influence symptom phenotype on leaves. EMBO J. 11:479-488.

24. Kasschau, K. D., and Carrington, J. C. 1998. A counterdefensive strategy of plant viruses: Suppression of posttranscriptional gene silencing. Cell 13:461-470.

25. Kavanagh, T., Goulden, M., Santa Cruz, S., Chapman, S., Barker, I., and Baulcombe, D. 1992. Molecular analysis of a resistance-breaking strain of potato virus X. Virology 189:609-617.

26. Kiraly, L., Cole, A. B., Bourque, J. E., and Schoelz, J. E. 1999. Systemic cell death is elicited by the interaction of a single gene in Nicotiana clevelandii and gene VI of cauliflower mosaic virus. Mol. Plant-Microbe Interact. 12:919-925.

27. Kohm, B. A., Goulden, M. G., Gilbert, J. E., Kavanagh, T. A., and Baulcombe, D. C. 1993. A potato virus X resistance gene mediates an induced, nonspecific resistance in protoplasts. Plant Cell 5:913-920.

28. Kunkel, B. N. 1996. A useful weed put to work: Genetic analysis of disease resistance in Arabidopsis thaliana. Trends Genet. 12:63-69.

29. Leisner, S. M., and Howell, S. H. 1992. Symptom variation in different Arabidopsis thaliana ecotypes produced by cauliflower mosaic virus. Phytopathology 82:1042-1046.

30. Leisner, S. M., Turgeon, R., and Howell, S. H. 1993. Effects of host plant development and genetic determinants on the long-distance movement of cauliflower mosaic virus in Arabidopsis. Plant Cell 5:191-202.

31. Matthews, R. E. F. 1991. Plant Virology, 3rd ed. Academic Press, San Diego, CA.

32. Melcher, U., Gardner, C. O., and Essenberg, R. C. 1981. Clones of cauliflower mosaic virus identified by molecular hybridization in turnip leaves. Plant Mol. Biol. 1:63-73.

33. Padgett, H. S., and Beachy, R. 1993. Analysis of a tobacco mosaic virus strain capable of overcoming $N$ gene-mediated resistance. Plant Cell 5: 
577-586.

34. Palanichelvam, K., Cole, A. B., Shababi, M., and Schoelz, J. E. 2000. Agroinfiltration of Cauliflower mosaic virus gene VI elicits hypersensitive response in Nicotiana species. Mol. Plant-Microbe Interact. 13:1275-1279.

35. Qiu, S. G., and Schoelz, J. E. 1992. Three regions of cauliflower mosaic virus strain W260 are involved in systemic infection of solanaceous hosts. Virology 190:773-782.

36. Qiu, S. G., Wintermantel, W. M., Sha, Y., and Schoelz, J. E. 1997. Lightdependent systemic infection of solanaceous species by cauliflower mosaic virus can be conditioned by a viral gene encoding an aphid transmission factor. Virology 227:180-188.

37. Rothnie, H. R., Chapdelaine, Y., and Hohn, T. 1994. Pararetroviruses and retroviruses: A comparative review of viral structure and gene expression strategies. Adv. Virus Res. 44:1-67.

38. Schoelz, J., Shepherd, R. J., and Daubert, S. 1986. Region VI of cauliflower mosaic virus encodes a host range determinant. Mol. Cell. Biol. 6:2632-2637.

39. Schoelz, J. E., Goldberg, K.-B., and Kiernan, J. 1991. Expression of cauliflower mosaic virus (CaMV) gene VI in transgenic Nicotiana biglovii complements a strain of CaMV defective in long-distance movement in nontransformed $N$. biglovii. Mol. Plant-Microbe Interact. 4:350-
355.

40. Schoelz, J. E., and Shepherd, R. J. 1988. Host range control of cauliflower mosaic virus. Virology 162:30-37.

41. Schoelz, J. E., and Wintermantel, W. M. 1993. Expansion of viral host range through complementation and recombination in transgenic plants. Plant Cell 5:1669-1679.

42. Staskawicz, B. J., Ausubel, F. M., Baker, B. J., Ellis, J. G., and Jones, J. D. G. 1995. Molecular genetics of plant disease resistance. Science 268:661-667.

43. Stratford, R., and Covey, S. 1989. Segregation of cauliflower mosaic virus symptom genetic determinants. Virology 172:451-459.

44. Tang, W., and Leisner, S. M. 1997. Cauliflower mosaic virus isolate NY8153 breaks resistance in Arabidopsis ecotype En-2. Phytopathology 87:792-798.

45. Waterhouse, P. M., Smith, N. A., and Wang, M.-B. 1999. Virus resistance and gene silencing: Killing the messenger. Trends Plant Sci. 4:452-457.

46. Wintermantel, W. M., Anderson, E. J., and Schoelz, J. E. 1993. Identification of domains within gene VI of cauliflower mosaic virus that influence systemic infection of Nicotiana biglovii in a light-dependent manner. Virology 196:789-798.

47. Wolffe, A. P., and Matzke, M. A. 1999. Epigenetics: Regulation through repression. Science 286:481-486. 